\title{
Produto a base de yacon e modulação da microbiota, perfil de ácidos graxo e lipídico em ratas ovariectomizadas
}

\author{
Product based yacon and modulation of \\ microbiota, fatty acid profile and lipid \\ in ovariectomized female rats
}

Joice de Fátima Laureano MARTINS'

Viviane da Cruz RAFAEL ${ }^{1}$

Edimar Aparecida FILOMENA ${ }^{1}$

Fabiana Carvalho RODRIGUES 2

Sirlene Souza Rodrigues SARTORI ${ }^{3}$

Célia Lúcia de Luces Fortes FERREIRA ${ }^{1}$

R E S U M O

\section{Objetivo}

Este trabalho avaliou a modulação da microbiota gastrointestinal, do perfil de ácidos orgânicos e de lipídeos em ratas Wistar ovariectomizadas, sendo que algumas receberam dieta suplementada com $6 \%$ de fruto-oligossacarídeos e inulina, a partir do produto a base de yacon, e outras não.

\section{Métodos}

Analisou-se o peso do ceco, pH e ácidos orgânicos, microbiota do conteúdo cecal, colesterol total e frações.

\section{Resultados}

No grupo que recebeu a dieta suplementada durante todo o experimento ocorreu modulação benéfica da microbiota intestinal em função da fermentação dos fruto-oligossacarídeos/inulina, bem como aumento do perfil de lactato $(p<0,05)$ e do nível de lipoproteina alta densidade $(p<0,05)$.

\footnotetext{
${ }^{1}$ Universidade Federal de Viçosa, Departamento de Tecnologia de Alimentos, Programa de Pós-Graduação em Ciências e Tecnologia de Alimentos. Av. Peter Henry Rolfs, s/n., Campus Universitário, 6570-900, Viçosa, MG, Brasil. Correspondência para/Correspondence to: JFL MARTINS. E-mail: <martinsjfl@yahoo.com.br>.

2 Instituto Federal de Educação, Ciência e Tecnologia do Espírito Santo, Curso de Engenharia de Alimentos. Vitória, ES, Brasil.

3 Universidade Federal de Viçosa, Curso de Biologia, Departamento de Biologia Animal. Viçosa, MG, Brasil.

Artigo elaborado a partir da tese de JFL MARTINS, intitulada: "Efeito de um produto a base de yacon (smallanthus shonchifolius) no controle da massa corpórea, no perfil de lipídeos e na toxicidade crônica em ratas Wistar ovariectomizadas". Universidade Federal de Viçosa; 2014.
} 


\section{Conclusão}

Isso sugere que o hábito de consumo contínuo do yacon tem potencial para modular a microbiota intestinal, o perfil de ácidos orgânicos e para diminuir as dislipidemias.

Palavras-chave: Dislipidemias. Ovariectomia. Prebióticos. Yacon.

\section{A B S T R A C T}

\section{Objective}

Fructans, a type of inulin present in yacon based products, can modulate microbiota and fatty acid profile, performing many beneficial roles. From this perspective, this study assessed the modulation of the gastrointestinal microbiota, organic acid profile, and lipid profile of ovariectomized Wistar rats fed or not a diet containing 6\% fructooligosaccharides and inulin from a yacon based product.

\section{Methods}

Cecum weight, pH, and organic acids, cecal content microbiota, total cholesterol, and fractions were analyzed.

\section{Results}

The group fed the diet supplemented with fructooligosaccharides and inulin during the study period experienced beneficial modulation of their intestinal microbiota stemming from fructooligosaccharide/inulin fermentation and increased lactate profile $(p<0.05)$ and high-density lipoprotein cholesterol $(p<0.05)$.

\section{Conclusion}

This suggests that regular yacon intake can potentially modulate the intestinal microbiota and organic acid profile, and reduce dyslipidemia.

Keywords: Dyslipidemias. Ovariectomy. Prebiotics. Yacon.

\section{N T R O D U Ç Ã O}

Atualmente, há um grande foco no papel da alimentação saudável para a promoção da saúde e do bem-estar individual' . Nesse contexto, grande destaque vem sendo dado aos prebióticos que, segundo a Food and Agriculture Organization (FAO, Organização das Nações Unidas para Agricultura e Alimentação), são "ingredientes não digeríveis que afetam beneficamente o hospedeiro pelo estímulo seletivo do crescimento e, ou atividade de uma ou de um número limitado de bactérias no cólon" 2 . Os alimentos funcionais apresentam substâncias, denominadas compostos bioativos, com distintas funções biológicas, dentre os quais encontram-se os Fruto-Oligossacarídeos (FOS), um oligossacarídeo, e a inulina, um polissacarídeo. Em ambos, predominam ligações glicosídicas do tipo frutosil-frutose $\beta(2-1)$, as quais conferem exclusivas propriedades estruturais e fisiológicas ${ }^{3}$. Tanto o FOS quanto a insulina estão presentes no yacon (Smallanthus sonchifolius), planta pertencente à família Asteraceae, originária da região dos Andes e que possui raízes tuberosas subterrâneas ${ }^{4}$.

Os oligossacarídeos prebióticos presente no yacon são seletivamente degradados no cólon por bactérias probióticas, uma vez que mamíferos não possuem enzimas capazes de quebrar essas ligações tipo $\beta(2-1)^{5}$. Isso resulta em modulação da microbiota ${ }^{2}$ e geração de metabólitos bioativos ou ácidos orgânicos de cadeira curta ${ }^{6}$ que desempenham diversas funções, com destaque para modulação da concentração sérica de colesterol ${ }^{7}$ e dos níveis séricos de triglicerídeos ${ }^{8}$. Essas comorbidades são tendenciadas pela menopausa em função da hipoestrogenia, comum nesse período?. Essas afecções têm gerado perda da qualidade de vida de mulheres na menopausa e elevados gastos governamentais com medicamentos e internações. Diante dessa problemática, no presente estudo, avaliou-se o papel do produto elaborado a partir da raiz do yacon processada, Produto a Base de Yacon (PBY), fonte de FOS/inulina, 
sobre a modulação da microbiota, no que diz respeito aos ácidos orgânicos ao nível cecal, e no perfil lipídico de ratas Wistar ovariectomizadas.

\section{MÉ TO D O S}

Foram utilizadas ratas (Rattus norvegicus, variedade albinus, classe Rodentia) recém-desmamadas (28 dias) da raça Wistar, provenientes do Biotério Central do Centro de Ciências Biológicas e da Saúde da Universidade Federal de Viçosa. Os animais foram mantidos no Laboratório de Nutrição experimental em gaiolas individuais de aço inoxidável à $22 \pm 2^{\circ} \mathrm{C}$, luz controlada (fotoperíodo de 12 horas) e água ad libitum.

Os animais foram dispostos em diferentes grupos experimentais e receberam as dietas purificadas e manipuladas, acrescidas ou não de quantidades de PBY suficientes para fornecer uma dose de $6 \%$ de FOS/inulina ${ }^{10}$. Para isso, foi realizada a análise da composição centesimal e dos teores de carboidratos não digeríveis (inulina e FOS) no Centro de Raízes e Amidos Tropicais (Botucatu, SP) e, depois disso, substituiu-se os componentes da dieta seguindo a ordem: sacarose, maltodextrina e amido de milho. O volume dessa substituição variava de acordo com o teor de FOS/inulina encontrado, o qual, por sua vez, pode sofrer alterações de acordo com a época de plantio e de colheita ${ }^{11}$. Todas as dietas foram calculadas e equilibradas quanto aos nutrientes e ao valor energético e a mistura de fibras adicionada à dieta controle e à dieta teste foi minunciosamente calculada para não ultrapassar $50 \mathrm{~g} / \mathrm{kg}$ nas dietas AIN 93, G e AIN 93, M, explicitadas mais à frente.

O produto à base de yacon testado foi desenvolvido no Departamento de Tecnologia de Alimentos da Universidade Federal de Viçosa. No entanto, a descrição do seu desenvolvimento deve ser resguardada devido às exigências da solicitação de patente (INPI: 014110002964).

Na primeira fase do estudo, os animais receberam dieta manipulada de crescimento (AIN-93G) ${ }^{12}$ por 12 semanas e, na segunda, foi administrada dieta purificada manipulada de manutenção (AIN-93 M) ${ }^{12}$ por oito semanas. Todas elas foram administradas na forme de pellet. Os procedimentos experimentais foram aprovados pelo Comitê de Ética para pesquisas com animais da Universidade Federal de Viçosa, parecer $n^{\circ} 55 / 2011$

O estudo foi realizado de acordo com o delineamento experimental indicado na Figura 1. As ratas foram divididas em dois grupos por Delineamento Inteiramente Casualizado (DIC), sendo

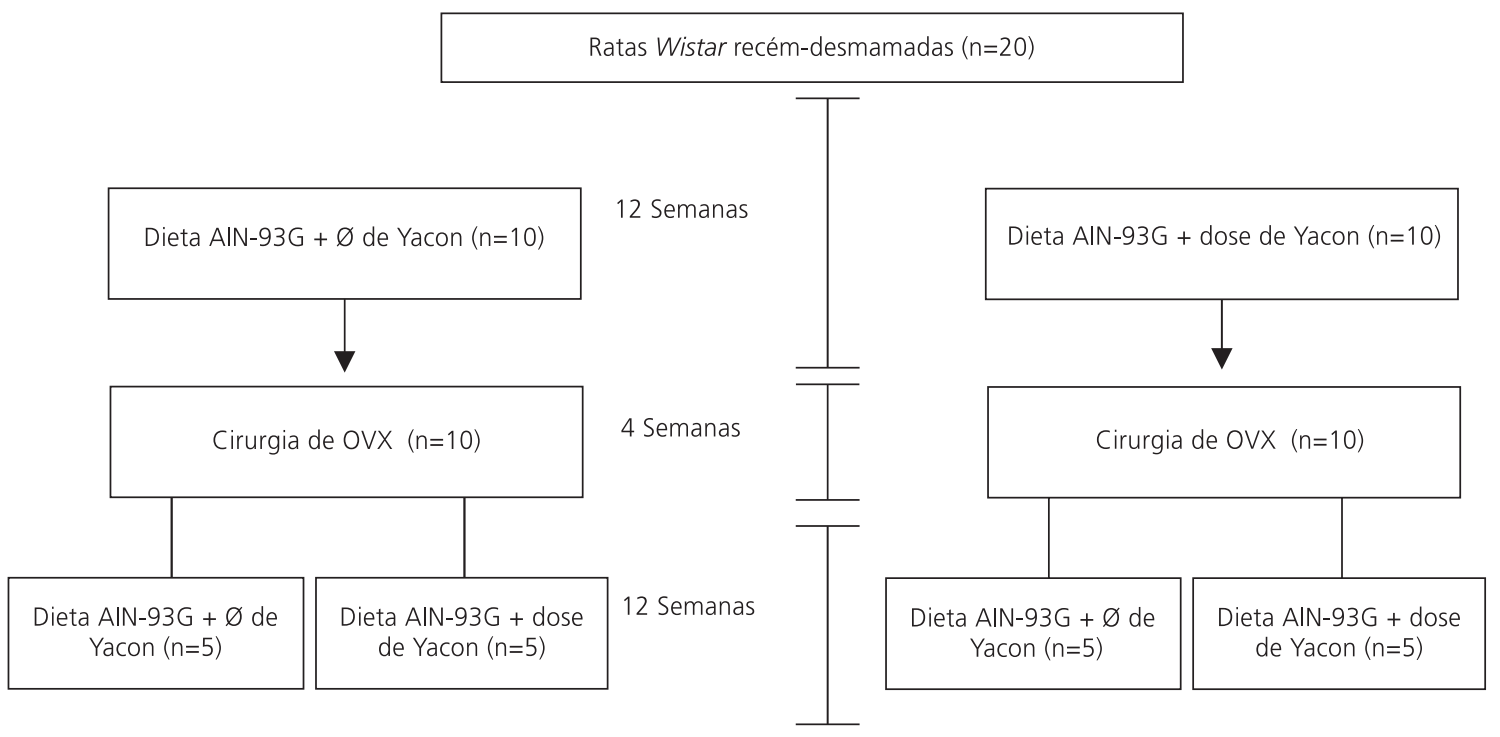

Figura 1. Organograma do experimento.

OVX: Ovariectomia 
um grupo teste $(n=10)$ e um grupo controle $(n=10)$ e foram acompanhadas por 24 semanas.

Durante 12 semanas, foi administrada aos animais a dieta de crescimento AIN-93G com e sem PBY. Após esse período, eles foram submetidos ao procedimento cirúrgico para retirada de ovário (ovariectomia - OVX) ou à simulação de retirada do órgão (celiotomia - SHAM). Na sequência, houve um wash out de quatro semanas para recuperação.

A OVX foi realizada a fim de simular a menopausa para avaliação da saúde óssea, da tendência ao ganho de peso e ao aumento da glicemia, da dislipidemia e do risco de doença cardiovascular ${ }^{13}$. Após a recuperação da cirurgia, os animais foram alocados em quatro grupos $(n=5)$, totalizando 20 unidades experimentais. Ao final do experimento, as ratas foram eutanasiadas por uma overdose de dióxido de carbono para realização das análises subsequentes. Os resultados das análises realizadas em ratas celiotomizadas foram um parâmetro interno para se ter um controle dos efeitos da cirurgia.

\section{Ovariectomia ou Laparotomia}

Ao atingir a fase adulta (12 semanas), metade dos animais foram submetidas à ovariectomia bilateral $(O V X)$ e a outra metade à cirurgia de celiotomia (SHAM) ou falsa ovariectomia para simular o efeito do estresse cirúrgico. Para os procedimentos cirúrgicos, as ratas foram anestesiadas, submetidas à depilação da região abdominal lateral e à assepsia local com álcool iodado. Em seguida, a pele e a musculatura foram incisadas longitudinalmente na linha medial próxima ao nível dos rins e abaixo da última costela, onde o ovário foi identificado e exposto. Nas ratas do grupo OVX, foi realizada a hemostasia através da ligação da parte superior da trompa com um fio; a excisão ovariana com posterior sutura da musculatura e da pele foram, então, realizadas. Para o grupo SHAM, após a exposição dos ovários, os órgãos foram recolocados na cavidade abdo- minal com posterior sutura da musculatura e da pele.

Nas primeiras cinco horas após as cirurgias, os animais permaneceram em câmera aquecida, a fim de manter a temperatura corporal. Sequencialmente, procedeu-se um wash out para recuperação, com suspensão dos tratamentos por quatro semanas. Seguiu-se administração da dieta AIN-93M ${ }^{12}$, acrescida ou não de $6 \%$ de FOS/inulina (de PBY), durante oito semanas.

\section{Análises bioquímicas do soro}

Após eutanásia, o sangue foi coletado por punção cardíaca com auxílio de seringas descartáveis. As amostras foram centrifugadas a 2.865 x g por 15 minutos (Fanem-204, São Paulo, Brasil) para obtenção do soro requerido na análise do perfil de lipídeos (colesterol total, High Density Lipoprotein-cholesterol [HDL-c], Low Density Lipoprotein-cholesterol [LDL-c] e triglicerídeos). Todos os procedimentos foram realizados de acordo com protocolos dos fabricantes (Bioclin ${ }^{\circledR}$, Santa Branca, Belo Horizonte, Brasil) dos kits colorimétricos e enzimáticos. Os índices de colesterol total/HDL e LDL-c/HDL-c também foram determinados.

\section{Avaliação do peso dos órgãos e ácidos graxos de cadeia curta no conteúdo cecal}

Ao final do experimento, os animais foram eutanasiados em câmara de $\mathrm{CO}_{2}$. Todos os procedimentos seguiram rigorosamente as normas do Comitê de Ética. O pH cecal foi avaliado in situ por inserção de um eletrodo na junção íleo-cecal. O ceco foi pesado e determinado o peso relativo conforme a equação: [peso relativo do ceco $=$ peso do ceco (g) $\div$ peso corporal final (g)]. O peso das ratas foi aferido em balança da marca Bel (Bel, Piracicaba, São Paulo, Brasil).

O conteúdo cecal foi coletado em sacos plásticos estéreis de polietileno da marca WhirlPak (Distribuidor: Nasco, United States of America) 
com capacidade de $100 \mathrm{~mL}$. Para determinação dos ácido acético, propiônico e butírico (Ácidos Graxos de Cadeia Curta [AGCC]), foi utilizada metodologia descrita por Smiricky-Tjardes et al. ${ }^{14}$. Às amostras do conteúdo cecal foram adicionados, em tubo tipo Eppendorf, 0,5 mL de ácido meta-fosfórico a $25 \%$ com posterior agitação em vortex. Depois desse procedimento, as amostrar foram mantidas em repouso por 30 minutos à temperatura ambiente $\left( \pm 25^{\circ} \mathrm{C}\right)$. Foram, então, centrifugadas em micro centrífuga refrigerada (Marca Centrifuge, modelo 5804 R, Distribuidor, Eppendorf do Brasil, São Paulo, Brasil) a 14263xg por 30 minutos. O sobrenadante foi transferido para outro tubo tipo Eppendorf sendo novamente centrifugado por 20 minutos nas mesmas condições descritas anteriormente. Posteriormente, o sobrenadante correspondente a cada amostra foi separado em vials individuais, sendo adicionados mais $4 \mathrm{~mL}$ de ácido meta-fosfórico a $25 \%$ e seguindo-se com o congelamento a $-20^{\circ} \mathrm{C}$.

Após essa etapa, as amostras foram analisadas por meio de Cromatografia Líquida de Alta Eficiência (HPLC, High Performance Liquid Chromatography), em cromatógrafo SHIMADZU, modelo SPD-10AVP (Distribuidor SHIMADZU do Brasil, São Paulo, Brasil), acoplado ao Detector Ultra Violeta utilizando-se comprimento de onda de 210 nm; coluna C18 (fase reversa) da marca BIORAD (Distribuidor Bio-Rad Laboratórios Brasil, Rio de Janeiro, Brasil), com $30 \mathrm{~cm} \times 4,5 \mathrm{~mm}$ de diâmetro, fluxo na coluna de $0,8 \mathrm{~mL} /$ minuto, pressão na coluna de 160 kgf; fase móvel: água em $1 \%$ de ácido orto fosfórico e volume injetado de $20 \mathrm{~mL}$.

Para análise microbiológica, foi retirado o conteúdo cecal de forma asséptica e cada amostra sofreu diluições seriadas para respectivas análises, que compreenderam determinações de micro-organismos do gênero Bifidobacterium, Lactobacillus, Clostridium, anaeróbios totais e coliformes. Após a diluição para concentração $\left(10^{-1}\right)$ utilizando caldo Brain Heart Infusion (BHI, Difco/Beckton Dickinson), as amostras foram congeladas e as diluições subsequentes foram reali- zadas com água de diluição proveniente da diluição de solução estoque de tampão fosfato e todas as inoculações foram realizadas pelo método de pour plate.

Para análise de micro-organismos do gênero Bifidobacterium, as amostras foram inoculadas em Ágar MRS (De Mann, Rogosa e Sharpe, Difco/ Beckton Dickinson) modificado com adição de cisteína 0,05\% (w/v). Esta foi previamente esterilizada com o uso de membrana Millipore 0,22 $\mu \mathrm{m}$ (Millipore Corporation, Medford, Massachusetts, United States of America). As placas foram incubadas a $37^{\circ} \mathrm{C} / 48 \mathrm{~h}$ em jarras de anaerobiose (GasPak, BBL, Cockeysville, Maryland, United States of America) contendo geradores de $\mathrm{CO}_{2} \mathrm{e}$ $\mathrm{H}_{2}$ (Anaerobac, Probac, São Paulo, Brasil).

Já para os micro-organismos do gênero Lactobacillus, as amostras foram inoculadas em Ágar MRS e incubadas a $37^{\circ} \mathrm{C} / 48 \mathrm{~h}$ em jarras de anaerobiose (GasPak, BBL, Cockeysville, Maryland, United States of America) contendo geradores de $\mathrm{CO}_{2}$ e $\mathrm{H}_{2}$ (Anaerobac, Probac, São Paulo, Brasil). Nas análises de anaeróbios totais, as amostras foram inoculadas em ágar Wilkin Chalgren (DifcoTM Interlab, São Paulo) e incubadas a $35^{\circ} \mathrm{C} / 24 \mathrm{~h}$ nas mesmas jarras de anaerobiose já descritas, também contendo geradores e $\mathrm{CO}_{2}$ e $\mathrm{H}_{2}$

Para determinação de micro-organimos do gênero Clostridium as amostras foram inoculadas em ágar Reinforced Clostridial Medium (DifcoTM Interlab, São Paulo, Brasil). As placas foram incubadas a $37^{\circ} \mathrm{C} / 48 \mathrm{~h}$ nas jarras de anaerobiose com geradores de $\mathrm{CO}_{2}$ e $\mathrm{H}_{2}$. Com relação à enumeração de coliformes, foi realizada inoculação em ágar Violet Red Bile (DifcoTM Interlab, São Paulo, Brasil) pelo método pour plate com sobrecamada do mesmo ágar, de acordo com a metodologia da American Public Health Association ${ }^{15}$.

Após o período de incubação, foram feitas contagens das Unidades Formadoras de Colônias (UFC) em contador de colônias, estabelecendo a contagem de micro-organismos por meio do nú- 
mero em UFC/g, multiplicando o número de colônias típicas pelo inverso da diluição (UFC/g $=\mathrm{N}^{\circ}$ de colônias/diluição). Os dados foram expressos em log de UFC por grama.

\section{Análise Estatística}

As Análises de Variância (ANOVA) e regressão linear foram realizadas no software Statistical Analysis System (SAS ${ }^{\circledR}$, versão 9.1 Institute Inc., North Carolina, United States of America, 1989) licenciado para a Universidade Federal de Viçosa. Considerou-se um nível de significância de 5\% para todas as análises. O pós-teste utilizado foi o método Ducan.

\section{RES ULTA D O S}

Na Tabela 1 encontram-se os dados das dosagens de ácidos orgânicos (lático, butírico, propiônico e acético) e pH do conteúdo cecal de ratas ovariectomizadas (OVX) que receberam ou não dieta suplementada com $6 \%$ de FOS/inulina do produto a base de yacon. Ovariectomia é a cirurgia de retirada dos ovários que tem sido usada para induzir os efeitos da menopausa em animais, pois exclui a secreção do hormônio estrogênio; assim, é possível verificar os efeitos da menopausa e alternativas para prevenção de efeitos colaterais.
Observou-se de aumento de ácido lático $(p<0,05)$, principalmente no grupo que recebeu PBY continuamente. Os demais ácidos orgânicos não apresentaram diferenças estatísticas. Esses resultados são benéficos, pois a ação de micro-organimos no lúmen intestinal sobre oligo e polissacarídeos (especialmente os não digeríveis), bem como sobre as proteínas que não são completamente digeridas, resultam em produtos Como AGCC (acético, propiônico e butírico), gases $\left(\mathrm{H}_{2}\right.$ e $\left.\mathrm{CO}_{2}\right)$ e biomassa bacteriana. Os ácidos graxos de cadeia curta, ao serem absorvidos, fornecem energia para o hospedeiro e agem regulando vias metabólicas ${ }^{5}$, como as presentes na modulação da absorção de cálcio ${ }^{16}$, as estimuladoras de hormônios da saciedade ${ }^{17,18}$ e as de controle da constipação intestinal ${ }^{19}$.

Os valores de $\mathrm{pH}$ foram semelhantes $(p>0,05)$ entre os grupos que receberam PBY durante todo o experimento. Esse fenômeno é interessante, pois a acidificação do ceco pode facilitar a absorção do cálcio e, assim, desfavorecer o desenvolvimento da osteoporose, fator de suma importância para mulheres na menopausa. Esses resultados corroboram os achados de Lobo et al. ${ }^{4}$, Rodrigues et al. ${ }^{7}$, Paula ${ }^{10}$ e Sant'Anna \& Ferreira ${ }^{19}$, que avaliaram a ação dos FOS/inulina sobre o pH, detectando a diminuição do mesmo.

A massa relativa do ceco (Figura 2) foi maior $(p>0,05)$ no grupo que recebeu dieta

Tabela 1. Ácidos orgânicos (mg/g) e pH em conteúdo fecal de ratas ovariectomizadas e alimentadas com dietas adicionadas ou não de $6 \%$ de fruto-oligossacarídeos/inulina de produto a base de yacon, durante 24 horas.

\begin{tabular}{|c|c|c|c|c|c|c|c|c|c|c|}
\hline \multirow{3}{*}{ Grupos } & \multicolumn{8}{|c|}{ Ácidos orgânicos } & \multirow{2}{*}{\multicolumn{2}{|c|}{$\mathrm{pH}$}} \\
\hline & \multicolumn{2}{|c|}{ Lático } & \multicolumn{2}{|c|}{ Butírico } & \multicolumn{2}{|c|}{ Propiônico } & \multicolumn{2}{|c|}{ Acético } & & \\
\hline & $M$ & DP & $M$ & DP & $M$ & DP & $M$ & $\mathrm{DP}$ & $M$ & DP \\
\hline $\mathrm{G} 1$ & 0,103 & $0,019^{a}$ & 1,779 & $0,238^{a, b}$ & 0,757 & $0,412^{a, b}$ & 1,857 & $1,225^{\mathbf{a}, \mathbf{b}}$ & 6,88 & $0,13^{a}$ \\
\hline G2 & 0,114 & $0,083^{a}$ & 1,357 & $0,987^{a, b}$ & 0,955 & $0,289^{a}$ & 2,040 & $0,441^{a}$ & 6,79 & $0,27^{a}$ \\
\hline G3 & 0,038 & $0,006^{b}$ & 1,053 & $0,222^{b}$ & 0,440 & $0,154^{b}$ & 1,075 & $0,200^{\mathbf{b}}$ & 6,79 & $0,29^{a}$ \\
\hline G4 & 0,256 & $0,036^{c}$ & 1,944 & $0,191^{a}$ & 1,112 & $0,272^{a}$ & 2,268 & $0,229^{a}$ & 6,77 & $0,25^{a}$ \\
\hline
\end{tabular}

Nota: Médias seguidas de letras iguais em uma mesma coluna não diferiram entre si ao nível de significância de 5\% pelo teste Ducan. G1: Recebeu dieta controle - OVX - continuou recebendo dieta controle $(n=5)$; G2: Recebeu dieta controle - OVX - passou a receber dieta com PBY ( $n=5$ ); $G 3$ : Recebeu dieta com PBY-OVX - passou a receber dieta controle ( $n=5)$; G4: Recebeu dieta com PBY-OVX-continuou recebendo dieta com PBY ( $n=5$ ). OVX: Ovariectomizadas; PBY: Produto a Base de Yacon; M: Média; DP: Desvio-Padrão. 


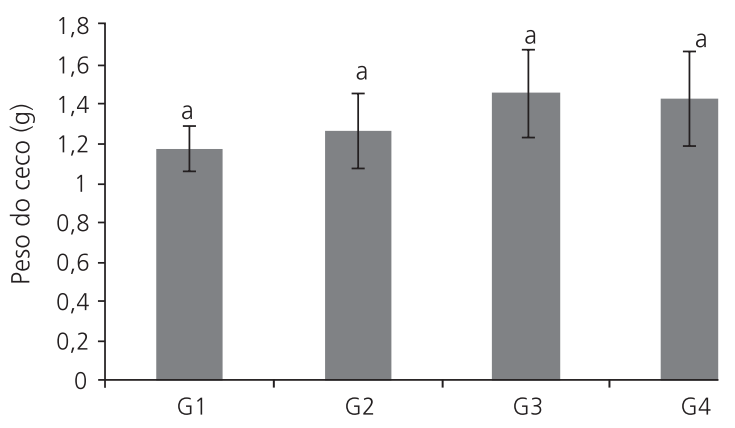

Figura 2. Massa relativa do ceco de ratas ovarioectomizadas, alimentadas com dieta adicionada ou não de 6\% FOS/ inulina durante 24 semanas e que delineadas em diferentes condições experimentais: G1: dieta controle OVX - dieta controle ( $n=5)$; G2: dieta controle - OVX dieta com PBY $(n=5)$; G3: dieta com PBY-OVX - dieta controle ( $n=5)$; G4: dieta com PBY-OVX - dieta com $\operatorname{PBY}(n=5)$.

Nota: FOS: Fruto-oligossacarídeos; OVX: Ovariectomia; PBY: Produtor a base de Yacon.

contendo PBY. O grupo G1, sem PBY durante todo o experimento, apresentou valores de massa do ceco menores. Esse resultado corrobora os de Lobo et al. ${ }^{4}$, os quais constataram aumento da massa do ceco dos ratos que consumiram $5 \%$ e $7,5 \%$ de FOS da farinha de yacon. Também está de acordo com os estudos de Rodrigues et al. ${ }^{7}$, que administraram farinha de yacon à dieta de ratos Wistar e observaram alteração na massa do ceco. Segundo Roberfroid ${ }^{5}$, a maior massa desse órgão pode estar relacionada ao efeito osmótico do FOS/inulina, o qual promove retenção de água no tecido. Esse fenômeno também foi relatado por Weaver et al. ${ }^{16}$, que utilizaram FOS/inulina sob a forma purificada em ratos. Esse efeito está associado à produção de AGCC, a qual promove hipertrofia da mucosa ${ }^{20}$ através do favorecimento da atividade metabólica no ceco. Entretanto, altas doses de FOS/inulina, assim como todo substrato fermentável no intestino grosso, podem promover desconforto por meio da produção de gases ou mesmo agir como laxante, causando diarreia ${ }^{5,18}$. Assim, deve-se ressaltar a importância de estudos que avaliem, em longo prazo, a dose de FOS/inulina adequada.

Como exposto na Tabela 2, não foi observada diferença estatística entre os grupos $(p>0,05)$ para a contagem de Bifidobacterium, Lactobacillus, anaeróbios, coliformes e Clostridium. Ao avaliar os dados de análise microbiológica, observou-se uma tendência ao aumento na contagem de Bifidobacterium $(p>0,05)$ no grupo que recebeu PBY durante todo o experimento (G4), o que reforça o resultado do aumento dos níveis de ácido lático $(p<0,05)$ observado no mesmo grupo $(\mathrm{G} 4)$. Esse fato sugere maior atividade de bactérias bífidas em consequência do estímulo advindo da dieta contendo PBY. Dentre os AGCC, a concentração de acetato foi $22,13 \%$ maior no grupo que recebeu PBY continuamente, reforçando a atuação de bactérias bífidas. Esse resultado é positivo, pois a fermentação por bactérias bífidas mantém o meio acidificado, facilitando a absorção

Tabela 2. Contagem de micro-organismos (log 10) em conteúdo cecal de ratas ovariectomizadas que receberam dieta adicionada ou não com $6 \%$ de fruto-oligossacarídeos/inulina de produto a base de yacon durante 24 semanas.

\begin{tabular}{|c|c|c|c|c|c|c|c|c|}
\hline \multirow{3}{*}{ Gênero } & \multicolumn{8}{|c|}{ Grupos } \\
\hline & \multicolumn{2}{|c|}{ G1 } & \multicolumn{2}{|c|}{ G2 } & \multicolumn{2}{|c|}{ G3 } & \multicolumn{2}{|c|}{ G4 } \\
\hline & $M$ & $\mathrm{DP}$ & $M$ & DP & $M$ & $\mathrm{DP}$ & $M$ & DP \\
\hline Bifidobacterium & 4,70 & $0,36^{\mathrm{a}}$ & 5,46 & $1,69^{a}$ & 5,61 & $0,8^{a}$ & 6,34 & $0,72^{\mathrm{a}}$ \\
\hline Lactobacillus & 5,11 & $0,50^{\mathrm{a}}$ & 5,48 & $1,58^{\mathrm{a}}$ & 5,61 & $0,7^{\mathrm{a}}$ & 6,07 & $0,83^{a}$ \\
\hline Anaeróbios & 6,27 & $1,04^{\mathrm{a}}$ & 6,52 & $1,10^{\mathrm{a}}$ & 6,42 & $0,6^{\mathrm{a}}$ & 6,92 & $0,28^{a}$ \\
\hline Coliformes & 6,87 & $0,13^{\mathrm{a}}$ & 6,60 & $0,29^{a}$ & 6,40 & $0,4^{\mathrm{a}}$ & 6,64 & $0,56^{\mathrm{a}}$ \\
\hline Clostridium & 5,61 & $0,60^{\mathrm{a}}$ & 6,06 & $0,88^{a}$ & 6,00 & $0,8^{a}$ & 6,28 & $0,42^{a}$ \\
\hline
\end{tabular}

Nota: Médias seguidas de letras iguais em uma mesma coluna não diferiram entre si ao nível de significância de 5\% pelo teste Ducan. G1: Recebeu dieta controle - OVX - continuou recebendo dieta controle $(n=5)$; $G 2$ : Recebeu dieta controle - OVX - passou a receber dieta com PBY ( $n=5$ ); $G 3$ : Recebeu dieta com PBY-OVX - passou a receber dieta controle $(n=5)$; $G 4$ : Recebeu dieta com PBY-OVX - continuou recebendo dieta com PBY ( $n=5)$. OVX: Ovariectomizadas; PBY: Produto a Base de Yacon; M: Média; DP: Desvio-Padrão. 
de alguns minerais e podendo ajudar na modulação da saúde óssea. Além disso, o meio ácido inibe o crescimento de patógenos e diminui o risco de infecções ${ }^{21}$.

No presente estudo, os grupos que receberam PBY ( $G 2$ e G3) em algum momento do experimento e, mais especificamente, o que recebeu PBY durante todo experimento (G4), tiveram tendência a uma contagem maior de anaeróbios totais que os demais grupos, sugerindo uma mudança na composição da microbiota intestinal. Essa mudança é benéfica, pois, com a fermentação bacteriana, há também um aumento da água no lúmen do intestino, resultando em diluição do conteúdo e manutenção da pressão osmótica. Todo esse processo melhora a constipação intestinal $^{19}$.

Já o aumento $(p>0,05)$ dos níveis de butirato foi detectado no grupo que recebeu PBY durante todo experimento (G4). Esse resultado corrobora os dados relativos à microbiota intestinal, tendo sido encontrado um aumento na quantidade de micro-organismos do grupo dos Clostridium sp., embora sem diferença estatística $(p>0,05)$. Esse aumento, segundo Gibson et al. ${ }^{22}$, está diretamente relacionado à produção de butirato. Nos estudos realizados por Sant'Anna \& Ferreira ${ }^{19}$ avaliando os efeitos de PBY na modulação da constipação intestinal, observou-se aumento na quantidade de Clostridium sp. e maior produção de butirato, também com $(p>0,05)$. Pesquisas realizadas por Rodrigues et al. ${ }^{7}$ e Paturi et al. ${ }^{23}$ com suplementação de farinha de yacon obtiveram resultados semelhantes aos aqui descritos.

Vale salientar que o presente estudo e os de Rodrigues et al. ${ }^{7}$, Paula ${ }^{10}$ e Sant'Anna \& Ferreira ${ }^{19}$ avaliaram o efeito de um produto alimentício (PBY ou farinha de yacon) fonte de FOS e inulina, ao passo que os demais utilizaram esses compostos na forma purificada. A matriz alimentar do PBY apresenta múltiplas funções, pois além de FOS e inulina, que agem como prebióticos, possui compostos fenólicos com grande capa- cidade antioxidante ${ }^{11}$ e que agem na eliminação de pré-carcinógenos, bem como protegem as membranas celulares contra danos causados pelos radicais livres. Dessa maneira, pode-se dizer que tem um efeitos anticarcinogênico, anti-inflamatório, anticolesterolêmico e na modulação glicêmica?.

Em relação ao peso das ratas, observou-se diminuição do ganho de peso $(p<0,05)$, da circunferência abdominal $(p<0,05)$, do índice de massa corporal e do percentual de gordura corporal em animais que receberam PBY continuamente, ou seja, antes e após o procedimento cirúrgico, quando comparados aqueles que interromperam o consumo do PBY após a cirurgia. Também pôde ser observada uma diminuição expressiva do LDL-c no grupo que recebeu dieta com $6 \%$ de FOS/inulina durante todo o experimento (G4) (Tabela 3). Esse resultado é promissor, pois o risco de doenças cardiovasculares está intimamente relacionado a desordens lipídicas, sendo uma das comorbidades tendenciadas pela menopausa, comprometendo a qualidade de vida e gerando gastos governamentais ${ }^{24}$.

Níveis elevados de colesterol total, LDL-C e triglicerídeos na corrente sanguínea podem levar a complicações cardiovasculares como aterosclerose $^{25}$. Entretanto, quanto maior o HDL-c, menor o risco de doenças cardiovasculares, uma vez que esta lipoproteína atua no transporte reverso de colesterol, ou seja, está envolvida no transporte de colesterol dos tecidos para o fígado. Assim, observou-se aumento do HDL-c no grupo que recebeu PBY durante todo experimento. Após a obtenção do perfil de lipídeos é possível calcular as razões colesterol total/HDL-c e LDL-c/HDL-c e há uma forte associação epidemiológica entre esses índices e a prevalência de doenças cardiovasculares $^{26}$. Neste estudo, observou-se uma tendência à diminuição desses índices.

Passos \& Park ${ }^{27}$, ao administrarem 10\% de FOS em ratos, observaram reduções de 15\% das taxas de colesterol total, 15\% nos fosfolipídeos e 25\% nos triglicerídios. Em pesquisas 
realizadas por Fiodarliso et al. ${ }^{28}$ em humanos levemente dislipidêmicos, constatou-se que, após administração de $18 \mathrm{~g} /$ dia de inulina, foram observadas diminuições de 8,5\% na concentração de colesterol total e de $14,4 \%$ na de LDL-c. Yamomoto et al. ${ }^{29}$ descreveram uma redução de $83 \%$ e $59 \%$ no colesterol sérico de ratos alimentados com 1 e $5 \%$ de FOS.

Já Kim \& Shin ${ }^{30}$ utilizaram as doses de $1 \%$ e $5 \%$ de extrato aquoso de chicória e $5 \%$ de inulina em modelo animal e não encontraram diferença significativa nas concentrações séricas de colesterol total e triacilgliceróis entre os tratamentos. As concentrações de HDL-c foram significativamente maiores nos grupos tratados com extrato de chicória e insulina e, para LDL-C, as concentrações obtidas foram menores que o controle.

Rodrigues et al. ${ }^{7}$, ao administrarem o prebiótico Farinha de Yacon (FY) com 4\% de FOS, probiótico na dose de 0,1 mL de $B$. longum e simbiótico (FY com 4\% de FOS + probiótico), em ratos durante 28 dias, observaram diminuição do colesterol $(p<0,05)$ naqueles que receberam prebiótico. No entanto, no grupo do probiótico, a concentração de colesterol total foi superior à do controle $(p<0,05)$. Os animais que receberam o simbiótico não diferiram do controle em relação a essa variável.
Dessa maneira, a ingestão de prebióticos resulta no aumento da excreção de sais biliares e, portanto, em maior mobilização de colesterol para a síntese desses sais. Isso resulta em diminuição dos níveis de colesterol e, consequentemente, no controle da dislipidemia ${ }^{31}$.

Em estudos realizados por Roberfroid ${ }^{32} \mathrm{e}$ Aarsland et al. ${ }^{33}$, ao ser administrada inulina em ratos, verificou-se a diminuição das concentrações séricas de Triglicerídeos (TG) em jejum e no estado pós-prandial. Acredita-se que essa diminuição seja resultante da Lipoproteína de Densidade Muito Baixa (VLDL, Very Low Density Lipoprotein) no plasma, o que resulta em decréscimo da síntese hepática de TG e catabolismo das lipoproteínas ricas nesse composto. Delzenne \& Kok ${ }^{34}$ sugerem que a hipotrigliceridemia ocorre em função da redução da reesterificação hepática dos ácidos graxos, ou seja, da redução da atividade lipogênica no fígado, resultando em menor quantidade de TG liberados na circulação.

Assim sendo, os resultados encontrados pela presente pesquisa em relação ao uso do PBY corroboram os achados benéficos descritos nos diversos estudos supracitados. Esse fato demonstra o efeito do PBY na modulação da microbiota intestinal, na estimulação da produção intestinal de ácidos orgânicos e na modulação lipídica. Entretanto, sugere-se que estudos clínicos sejam

Tabela 3. Perfil de lipídeos ( $\mathrm{mg} / \mathrm{dL}$ ) no soro de ratas ovariectomizadas e alimentadas ou não com $6 \%$ de fruto-oligossacarídeos/inulina de produto a base de yacon durante 24 semanas.

\begin{tabular}{|c|c|c|c|c|c|c|c|c|}
\hline \multirow{3}{*}{ Variáveis } & \multicolumn{8}{|c|}{ Grupos } \\
\hline & \multicolumn{2}{|c|}{ G1 } & \multicolumn{2}{|c|}{ G2 } & \multicolumn{2}{|c|}{ G3 } & \multicolumn{2}{|c|}{ G4 } \\
\hline & M & DP & M & DP & M & DP & M & $\mathrm{DP}$ \\
\hline Colesterol total & 180,52 & $11,98^{\mathrm{a}}$ & 162,27 & $19,64^{\mathrm{a}}$ & 170,48 & $35,15^{\mathrm{a}}$ & 157,65 & $29,91^{\mathrm{a}}$ \\
\hline HDL-C & 50,32 & $7,14^{a, b}$ & 49,47 & $4,11^{a, b}$ & 47,67 & $13,26^{\mathbf{b}}$ & 61,63 & $4,73^{\mathrm{a}}$ \\
\hline Colesterol total/HDL & 3,12 & $0,26^{a}$ & 3,28 & $0,31^{\mathrm{a}}$ & 4,01 & $2,17^{\mathrm{a}}$ & 2,94 & $0,30^{\mathrm{a}}$ \\
\hline LDL-C & 108,24 & $1,28^{b}$ & 94,00 & $13,88^{\mathbf{b}}$ & 104,93 & $18,16^{\mathbf{b}}$ & 79,26 & $18,04^{\mathrm{a}}$ \\
\hline LDL-C/HDL-C & 1,75 & $0,30^{\mathrm{a}}$ & 1,93 & $0,33^{\mathrm{a}}$ & 2,59 & $1,94^{\mathrm{a}}$ & 1,59 & $0,33^{\mathrm{a}}$ \\
\hline Triacilgliceróis & 109,80 & $17,81^{\mathrm{a}}$ & 94,00 & $8,26^{\mathrm{a}}$ & 89,40 & $18,65^{a}$ & 83,80 & $35,72^{\mathrm{a}}$ \\
\hline
\end{tabular}

Nota: Médias seguidas de letras iguais em uma mesma coluna não diferiram entre si ao nível de significância de $5 \%$ pelo teste Ducan. G1: Recebeu dieta controle - OVX - continuou recebendo dieta controle ( $n=5)$; G2: Recebeu dieta controle - OVX - passou a receber dieta com PBY $(n=5)$; G3: Recebeu dieta com PBY-OVX - passou a receber dieta controle ( $n=5)$; G4: Recebeu dieta com PBY-OVX - continuou recebendo dieta com $\operatorname{PBY}(n=5)$

HDL-c: High Density Lipoprotein-cholesterol; LDL-c: Low Density Lipoprotein-cholesterol; OVX: Ovariectomizadas; PBY: Produtor a Base de Yacon; M: Média; DP: Desvio-Padrão. 
realizados para que haja o estímulo ao consumo da raiz de yacon, um alimento prebiótico que tem se mostrado cada vez mais promissor.

\section{O N CLUS Ã O}

A modulação da microbiota do ceco, do perfil de ácidos orgânicos e do perfil lipídico, apresentada pelos resultados aqui encontrados, sugere a importância do uso continuo do PBY. Embora existam alguns estudos com o yacon, são escassos aqueles com o foco aqui descrito. Por conta disso, novas pesquisas devem ser realizadas visando o estímulo ao consumo da raiz de yacon ou de produtos à base de yacon.

\section{REFERÊ NCIAS}

1. World Health Organization. Diet, nutrition and the prevention of chronic diseases. Geneva: WHO; 2003.

2. Food and Agriculture Organization. Tecnical meeting on prebiotics: Food quality and standards service (AGNS). Rome: FAO; 2007.

3. Yıldiz S. The Metabolism of fructooligosaccharides and fructooligosaccharide-related compounds in plants. Food Rev Int. 2011; 27(1):16-50.

4. Lobo AR, Colli C, Alvares EP, Filisetti TMCC. Effects of fructans-containing yacon (Smallanthus sonchifolius Poepp and Endl.) flour on caecum mucosal morphometry, calcium and magnesium balance, and bone calcium retention in growing rats. Br J Nutr. 2007; 97(4):776-85.

5. Roberfroid MB. Introducing inulin-type fructans. $\mathrm{Br}$ J Nutr. 2005; 93(Suppl. 1):525-56.

6. Geyer M, Manrique I, Degen L, Beglinger C. Effect of yacon (smallanthus sonchifolius) on colonic transit time in healthy volunteers. Digestion. 2008; 78(1):30-3.

7. Rodrigues FCR, Castro ASB, Rodrigues VC, Fernandes SA, Fontes EAF, Oliveira TT, et al. Yacon flour and bifidobacterium longum modulate bone health in rats. J Med Food. 2012; 15(7):664-70.

8. Valentova K, Stejskal D, Bartek J, Dvorackova S, Kren V, Ulrichova J, et al. Maca (Lepidium meyenii) and yacon (Smallanthus sonchifolius) in combination with silymarin as food supplements: In vivo safety assessment: Food Chem Toxicol. 2008; 46(3):1006-13.
9. Silva IMC, Sá EQC. Alimentos funcionais: um enfoque gerontológico. Rev Bras Clín Méd. 2012; 10(1):24-8.

10. Paula HAA. Efeito de um produto à base de yacon (Smallanthus sonchifolius) na modulação de indicadores da saúde óssea em ratas wistar [doutorado]. Viçosa: Universidade de Federal de Viçosa; 2013.

11. Yun EY, Kim HS, Kim YE, Kang MK, Ma JE, Lee GD, et al. A case of anaphylaxis after the ingestion of yacon. Allergy Asthma Immunol Res. 2010; 2(2):149-52.

12. Reeves PC, Nielsen FH, Fahey GC. AIN-93 Purified diets for laboratory rodents: Final report of the American Institute of Nutrition Ad Hoc Writing Committee on the Reformulation of the AIN-76 A Rodent Diet. J Nutr. 1993; 123(11):1939-51.

13. Simões PA, Zamarioli A, Blóes P, Mazzocato FC, Pereira LHA, Volpon JB, et al. Effect of treadmill exercise on lumbar vertebrae in ovariectomized rats: Anthropometrical and mechanical analyses. Acta of Bioeng Biomech. 2008; 10(2):39-41.

14. Smiricky-Tjardes MR, Grieshop CM, Flickinger EA, Bauer LL, Fahey GC. Dietary galactooligosaccharides affect ileal and total-tract nutrient digestibility, ileal and fecal bacterial concentrations, and ileal fermentative characteristics of growing pigs. J Anim Sci. 2003; 81(10):2535-45.

15. American Public Health Association. Standard methods for the examination of dairy products. $17^{\text {th }}$ ed. Washington (DC): APHA; 2004.

16. Weaver CM, Martin R, Story JA, Hutchinson I, Sanders L. Novel fibers increase bone calcium content and strength beyond efficiency of large intestine fermentation. J Agric Food Chem. 2010; 58(16):8952-7.

17. Genta S, Cabrera W, Habiba N, Ponsb J, Carilloc IM, Graud A, et al. Yacon syrup: Beneficial effects on obesity and insulin resistance in humans. Clin Nutr. 2009; 28(2):182-7.

18. Genta S, Cabrera WM, Grau A, Sánchez SS. Subchronic 4-month oral toxicity study of dried Smallanthus sonchifolius (yacon) roots as a diet supplement in rats. Food Chem Toxicol. 2005; 43(11):1657-65.

19. Sant'Anna MSL, Ferreira CLLF. Yacon (Smallanthus sonchifolius) no controle das doenças crônicas nãotransmissíveis. Nutr Br. 2013; 12(5):310-4.

20. Havenaar R. Intestinal health functions of colonic microbial metabolites: A review. Beneficial Microbes. 2011; 2(2):103-14.

21. Rodriguez-Cabezas ME, Camuesco D, Arribas B, Garrido-Mesa N, Comalada M, Bailón E, et al. The combination of fructooligosaccharides and resistant 
starch shows prebiotic additive effects in rats. Clin Nutr. 2010; 29(6):832-9.

22. Gibson GR, Beatty ER, Wang X, Cummings JH. Selective stimulation of bifidobacteria in the human colon by oligofructose and inulin. Gastroenterol. 1995; 108(4):975-82.

23. Paturi G, Butts CA, Stoklosinski H, Ansell J. Effects of early dietary intervention with a fermentable fibre on colonic microbiota activity and mucin gene expression in newly weaned rats. J Funct Foods. 2012; 4(2):520-30.

24. American Diabetes Association. Standars of medical care in diabetes. Diabetes Care. 2010; 33(Suppl. 1):S11-S61.

25. Charland SL, Cziraky MJ, Quimbo R. Achieving optimal lipid values in patients with dyslipidemia is associated with reduced risk of cardiovascular events. J Clin Lipidol. 2008; 2(5):343-53.

26. Castelli WP. Epidemiology of coronary heart disease: The Framingham study. Am J Med. 1984; 27(2A):4-12.

27. Passos LML, Park YK. Frutoligossacarídeos: implicações na saúde humana e utilização em alimentos. Ciênc Rural. 2003; 33(2):385-90.

28. Fiodarliso M, Kok N, Desager JP, Goethal SF, Roberfroid M, Delzenne N. Dietary oligofructose lower triglycerides, phospholipids and cholesterol in serum and very low density lipoproteins of rats. Lipids. 1995; 30(2):163-7.
29. Yamomoto Y, Takahashi Y, Kawano M, Lizuka M, Matsumoto T, Shigeru $S$, et al. In vitro digestibilty and fermentability of levan and its hypocholesterolemic effects in rats. J Nutr Biochem. 1999; 10(1):13-8.

30. Kim M, Shin HS. The water-soluble extract of chicory influences serum and liver lipid concentrations, cecal short-chain fatty acid concentrations and fecal lipid excretion in rats. J Nutr. 1998; 128(10):1731-6.

31. Perucha VR. Propriedades funcionais da banana verde. Nutr Saúde e Perform. 2005 [acesso 2014 dez 8]; 26. Disponível em: http://www.brazilhost. com.br/bananaverde/propriedade.htm

32. Roberfroid MB. Prebiotics and probiotics: Are they functional foods? Am J Clin Nutr. 2000; 71(Suppl. 6):1682-7.

33. Aarsland A, Chinkes D, Wolfe RR. Contribuitions of de novo synthesis of fatty acids to total VLDL-trigliceride secretion during prolonged hyperglycemia/insulinemia in normal man. J Clin Invest. 1996; 98(9):2008-17.

34. Delzenne N, Kok N. Effects of fructans-type prebiotics on lipid metabolism. Am J Clin Nutr. 2001; 73(Suppl. 2):456-8.
Recebido: janeiro 13, 2015 Versão final: abril 25, 2016 Aprovado: maio 16, 2016 
